\title{
The analysis of performance level on an existing multi-story building structure using the time history based on the subduction earthquake source
}

\author{
Wisnu Erlangga ${ }^{l}$, Mochamad Teguh ${ }^{l}$, and Lalu Makrup ${ }^{l}$ \\ ${ }^{1}$ Department of Civil Engineering and Disaster Risk Management, Islamic University of Indonesia, Indonesia
}

\begin{abstract}
The use of time history in the building evaluation process is rarely done. Usually, the time history used is taken from a different location, with the building being evaluated so that the evaluation results become less valid. Each place has a different time history character that is why the analysis of structures using time history from other sites is not accurate. In this study, the time history used was sourced from subduction earthquake sources. For the time history used in the location of the study, a spectral matching process is needed to equalize the response spectra of the time history with the response spectra at the study location. The Alana Hotel is selected as a research object for building evaluation adopting SNI 03-1726-2012, FEMA 356, and ATC-40 as references with structural modeling using SAP2000. Based on the evaluation results, it can be summarized that displacement values at each floor do not exceed the maximum limit so that this building has fulfilled the requirements. The inter-level displacement due to earthquake loading does not exceed the limit so that this building is feasibly occupied. The performance level of the Alana Hotel is Immediate Occupancy (IO).
\end{abstract}

\section{Introduction}

Indonesia's location between the three major plates of the world causes the intensity of earthquakes in Indonesia is enormous compared to other countries in the world. An earthquake is a natural occurrence which until now, cannot be predicted when and where it will occur and can cause considerable losses, both properties, and loss of life. Thus the earthquake disaster has the potential to cause severe problems because it can cause damage and loss in large numbers. Earthquakes that occur in an area is an event that has a certain re-period (return period). Widodo [1] says that the estimated probability of an earthquake is based on scientific research that identifies areas that have a risk of earthquakes.

The intensity of earthquakes in Indonesia is enormous over the past 50 years. Yogyakarta is one of the provinces having moderate to high seismic activity in Indonesia. The 2006 Yogyakarta Earthquake had a strength of 6.3 SR with the epicenter at a depth of $10 \mathrm{~km}$ and was at coordinates $7,962^{\circ}$ LS and 110,458 ${ }^{\circ}$ East [2]. This condition shows that the Special Region of Yogyakarta has a high vulnerability to earthquake disasters. Yogyakarta Special Region also has a relatively large population, which causes a high level of risk to earthquake disasters. A collapsed building caused a large number of casualties due to the 2006 Yogyakarta Earthquake. The majority of collapsed buildings are houses where residents live, especially in Bantul Regency. The majority of the houses were not built and not designed to withstand earthquakes. If in a simple building such as a house, people feel worried that collapsing will occur, especially with high-rise residential buildings. In a story residential, it has a smaller risk compared to high-rise buildings. It is because the evacuation process when an earthquake occurs in a high-rise building takes longer, especially at the upper levels of the building. In the design of a structure, quantitative earthquake hazards should be considered [3]. Seismology, geology, geotechnics, and structural aspects are commonly categorized as earthquake hazards. One way to reduce the risk of earthquake disaster is to plan and build earthquakeresistant buildings [4]

One of the high-rise buildings in Yogyakarta is the Alana Hotel. The Alana Hotel Planning uses the old regulation, SNI-1726-2002. Changes to rules result in changes in earthquake risk design parameters where the risk of the earthquake in the new code regulation is higher than the old one. Evaluation of the structure is needed to determine the safety of the building structure that is adjusted to the new code regulations, SNI 03-1726-2012. Besides, the vertical configuration of building structures is irregular. The irregular shape of the building has the potential to cause a significant moment in the building's structural elements to behave nonlinearly. The effect of earthquakes on the structure is analyzed to determine the characteristics of earthquake motion and structural performance characteristics by considering the earthquake spectrum.

\footnotetext{
* Corresponding author: wisnuuangga $@$ gmail.com
} 
In the design and analysis of buildings, an engineer usually uses the earthquake load from response spectra. The use of time history is rarely done in building analysis because of the difficulty of obtaining accurate data. In general, time history used in the analysis of buildings is the recording of earthquakes from other places without the process of matching because of the difficulty of the matching process. The time history used in this research is the time history at bedrock. Time history in bedrock and time history on the surface have different values and shapes[5]. These differences cause differences in the response of building structures. Therefore this research was carried out to find out the structure performance due to time history on bedrock and time history on the surface.

\section{Theoretical basis}

\subsection{Modeling of the earthquake source zone}

The earthquake source zone is defined as an area that has the same earthquake degree, where each point in the zone has the same probability of future earthquakes. The earthquake source model is needed as a relationship between earthquake event data and calculation models used in determining the level of earthquake hazard. The modeling limits of an earthquake source zone used are as follows:

1. the depth of the earthquake source is limited to 200 $\mathrm{km}$,

2. the distance from the location of the earthquake source to the site reviewed is limited to $500 \mathrm{~km}$, and

3 . the attenuation function used for each model is the attenuation function which is considered following with the seismic characteristics and earthquake source model of the Indonesian region.

The earthquake source modeling is based on interpretations of known seismologist conditions from geological, geophysical, and seismological data. The earthquake source model can be classified in three (3) types including:

1. sources of subduction earthquakes, namely plate meeting zones where oceanic plates slam into continental plates or two continents which support each other and produce large earthquakes [6],

2. source of faults, namely shallow crustal faults that occur in faults that have been appropriately identified, and

3. source of background earthquake, which is an earthquake source that is not known. This earthquake source model is very suitable for areas where faults or faults have not been identified, but the area has a history of earthquake events. Earthquake events in the background zone are usually small to medium earthquakes.

\subsubsection{Subduction earthquake sources}

The Earthquake events due to thrust fault, normal fault, reverse slip, and strike-slip that occur along plate meetings can be classified as subduction zones. Subduction zones are divided into megathrust / interplate and Benioff / intraslab zones. The megathrust zone is at a depth of less than $50 \mathrm{~km}$, and the benzial area is at a depth of more than $50 \mathrm{~km}$, as shown in Fig. 1.

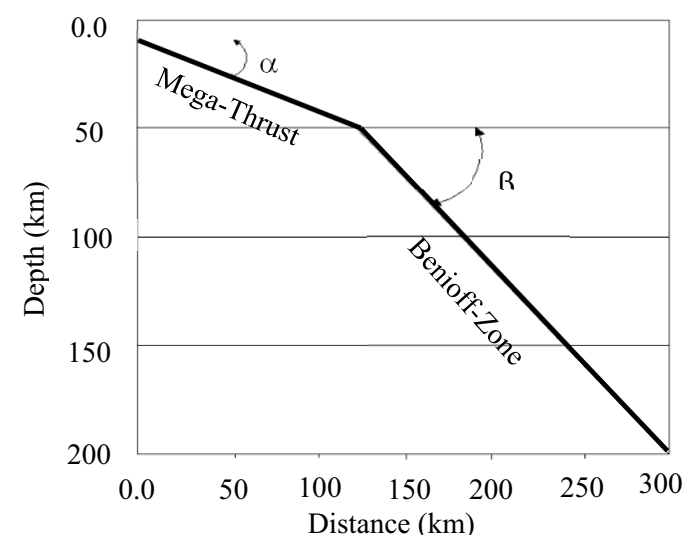

Fig. 1. Subduction zone model, consisting of megathrust and benioff zones[7]

\subsubsection{Shallow crustal sources}

The shallow crustal earthquake zone modeling includes the direction, length of the fault, coordinates, and depth position. This model is referred to as a three-dimensional earthquake source model because in calculating the probability of distance, the distance used comes from the site to the hypocenter.

\subsubsection{Earthquake source background}

This earthquake model predicts the possibility of a larger earthquake occurring around a small to moderate earthquake that has occurred before. This model is very suitable for areas where faults or faults have not been identified, but the area has a history of earthquake events. Earthquake events in the background zone are usually small to medium earthquakes. The earthquake catalog used for background source zone analysis is the main earthquake obtained from earthquake catalog data, which has removed the foreshock and aftershock earthquakes.

\subsection{Identification of earthquake source}

Table 1. Fault and subduction

\begin{tabular}{|c|c|}
\hline Fault & Subduction \\
\hline Scsunda & SouthSumatraMegatrust \\
\hline Cimandiri & SouthSumatraBenioff \\
\hline Lembang & JavaMegatrust1 \\
\hline Baribis & JavaBenioff1 \\
\hline Bumiayu & JawaMegatrust2 \\
\hline OpakFault & JawaBenioff2 \\
\hline Pati & JawaMegatrust3 \\
\hline Lasem & JawaBenioff3 \\
\hline FloresBackArc & NustraMegatrust \\
\hline Scsunda & NustraBenioff \\
\hline
\end{tabular}


In this study, the source of earthquake hazard, which is taken into account, is the source of earthquake fault and subduction located in Java, South Sumatra, and Sumba (NTT). The fault and subduction that are reviewed can be seen in Table 1.

\subsection{Perfomance levels}

The structural performance level is represented by a curve of the relationship between the base shear force and the displacement at the control point (the center of lateral force distribution). Also, it is shown how the overall structural collapse behavior towards lateral loading. The curve is obtained from the results of a non-linear static analysis or pushover analysis. From the explanation of each level of building performance due to earthquake loads, the deviation of the structure can be illustrated in Fig. 2.

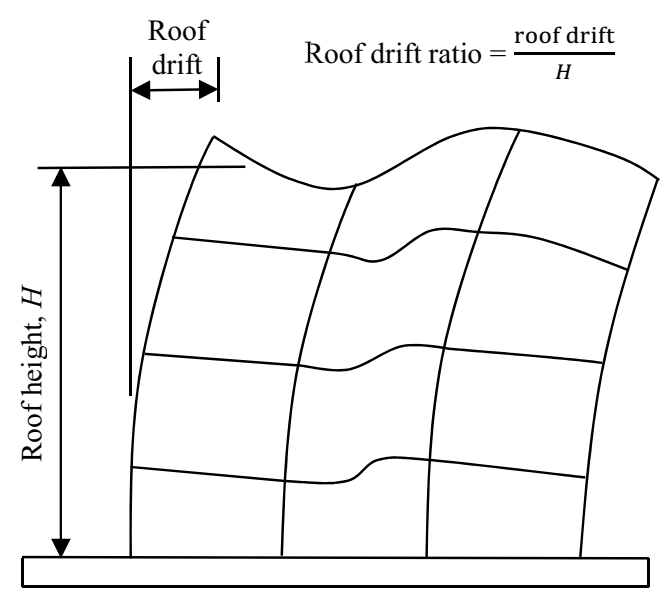

Fig. 2. Roof drift and roof drift ratio [7]

The relationship between the level of structural performance and the drift on the vertical elements of the lateral load-bearing system in the form of concrete frames can be seen in Table 2, based on FEMA 356. The deviation values in the table are typical values given to explain the overall structural response following various levels of structural performance.

Table 2. Limitation of drift ratio for performance level [8]

\begin{tabular}{|c|c|c|}
\hline Performance levels & Drift (\%) & Explanation \\
\hline Immediate & 1.0 & Transient \\
\hline Occupancy & 2.0 & $\begin{array}{c}\text { Transient } \\
\text { Permanent }\end{array}$ \\
\hline Life Safety & 1,0 & $\begin{array}{c}\text { Transient or } \\
\text { permanent }\end{array}$ \\
\hline
\end{tabular}

ATC-40 (1996) provides deformation limits for various levels of building structure performance, as shown in Table 3. A maximum total drift is defined as drift between levels in the displacement of the performance point. The maximum inelastic deviation is defined as the portion of the maximum total deviation below the melting point.
Table 3. Limitation of drift ratio for performance level [9]

\begin{tabular}{|c|c|c|c|c|}
\hline \multirow{2}{*}{$\begin{array}{c}\text { Drift } \\
\text { limitatio } \\
\mathbf{n}\end{array}$} & \multicolumn{4}{|c|}{ Level of structural performance } \\
\cline { 2 - 5 } & $\begin{array}{c}\text { Immediate } \\
\text { Occupanc } \\
\mathbf{y}\end{array}$ & $\begin{array}{c}\text { Damag } \\
\mathbf{e} \\
\text { Control }\end{array}$ & $\begin{array}{c}\text { Life } \\
\text { Safety }\end{array}$ & $\begin{array}{c}\text { Structura } \\
\text { I Stability }\end{array}$ \\
\hline $\begin{array}{c}\text { Maximum } \\
\text { total drift }\end{array}$ & 0.01 & $\begin{array}{c}0.01- \\
0.02\end{array}$ & 0.02 & $0.33 \cdot \frac{V_{i}}{P_{i}}$ \\
\hline $\begin{array}{c}\text { Maximum } \\
\text { inelastic } \\
\text { drift }\end{array}$ & 0.005 & $\begin{array}{c}0.005- \\
0.015\end{array}$ & $\begin{array}{c}\text { Not } \\
\text { limite } \\
\mathrm{d}\end{array}$ & $\begin{array}{c}\text { Not } \\
\text { limited }\end{array}$ \\
\hline
\end{tabular}

Note: Vi and Pi are the total shear force and the total gravity on floors ith, respectively.

\subsection{Service limit performance}

Service limit performance on the building structure is determined by the deviation between levels due to the influence of the earthquake plan. Limitation of deviation values aims to maintain the comfort of occupants, prevent non-structural damage, limit the occurrence of melting of steel, and excessive cracking of concrete.

\subsection{Ultimit limit performance}

The values for each of the parameters reviewed, which are calculated for various variants, must be combined using the squared root of the sum of the squares method (SRSS) or the complete quadratic combination method (CQC), following SNI 03-1726-2012. The CQC method must be used for each variable value, where the range of proximity has a significant cross-correlation between the translation and torque responses. Then to determine the value of the boundary, the recording is done on the intersection between floors. Inter-floor deviation from the design level should not exceed the deviation permit of floors between level floors $(\Delta a)$ for all levels. The intersection between the floors of the permitted level $(\Delta \mathrm{a})$ is obtained from the following Table 4.

Table 4. The intersection between the floors of the permitted level [10]

\begin{tabular}{|l|c|c|c|}
\hline \multirow{2}{*}{ Structure } & \multicolumn{3}{|c|}{ Risk category } \\
\cline { 2 - 4 } & I or II & \multicolumn{1}{|c|}{ III } & IV \\
\hline $\begin{array}{l}\text { Structure, apart from } \\
\text { the brick sliding wall } \\
\text { structure, levels or } \\
\text { less with interior } \\
\text { walls, partitions, } \\
\text { ceilings, and exterior } \\
\text { wall systems that } \\
\text { have been designed to } \\
\text { accommodate } \\
\text { intersections between } \\
\text { floors. }\end{array}$ & $0.025 h_{s x}$ & $0.020 h_{s x}$ & $0.015 h_{s x}$ \\
\hline $\begin{array}{l}\text { Shear wall structure } \\
\text { brick cantilever }\end{array}$ & $0.010 h_{s x}$ & $0.010 h_{s x}$ & $0.010 h_{s x}$ \\
\hline $\begin{array}{l}\text { Shear wall structure } \\
\text { other bricks }\end{array}$ & $0.007 h_{s x}$ & $0.007 h_{s x}$ & $0.007 h_{s x}$ \\
\hline All other structures & $0.020 h_{s x}$ & $0.015 h_{s x}$ & $0.010 h_{s x}$ \\
\hline
\end{tabular}

Note : $h_{s x}$ is a high level below level $\mathrm{x}$ 


\section{Results and Discussion}

The earthquake hazard analysis conducted in this study used the probabilistic method (PSHA) with an exceeded probability of $2 \%$ in 50 years of building age or equivalent to a return period of 2475 years. From the results of the analysis, a uniform hazard spectral was obtained. The process of hazard deaggregation is then performed; this process analyzes various sources of earthquake hazard that affect a location by predicting dominant distance and dominant magnitude. Dominant distance $(R)$ and dominant magnitude $(M w)$ are used as a reference in determining ground motion that is following the conditions of the research location. The spectral matching process needed to equalize the response spectra of the earthquake with the response spectra in the research location. Structure modeling and analysis are carried out on SAP2000 software. The following is a 3D view of the modeling done that can be seen in Fig. 3.

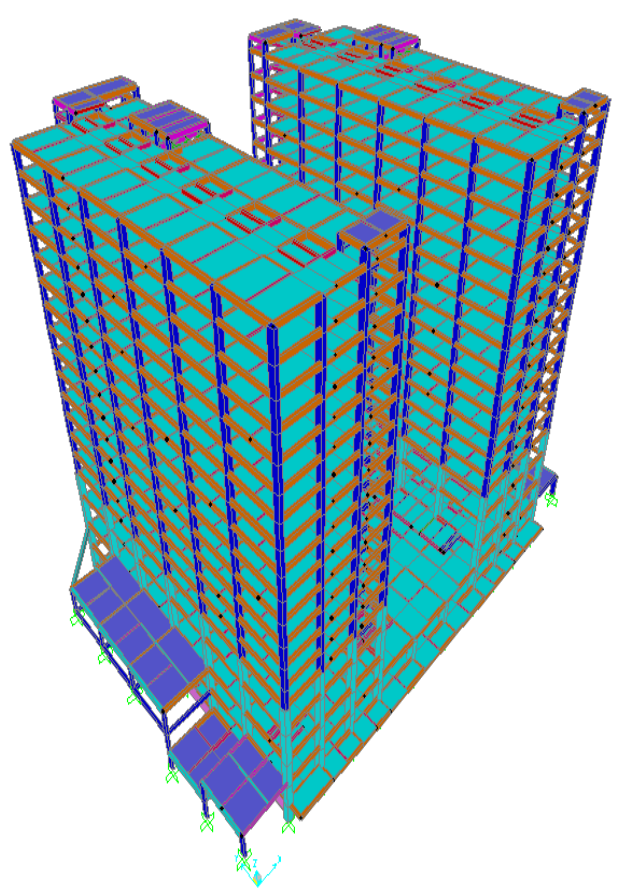

Fig. 3. Modeling on SAP2000

\subsection{Time history analysis}

\subsubsection{Time history on bedrock}

The time history data that used in this research is Hector Mine earthquake data in 1999 recorded on the LA Griffith Park Observatory earthquake recording station. This earthquake has a magnitude of 7.13, with a distance of $185.92 \mathrm{~km}$. In this study, the target spectra used is the spectral response in bedrock and will be used as a reference in spectral matching analysis for time history in this study. A comparison of time history before and after the matching process shows the resulting peak acceleration increase from the previous $0.0296 \mathrm{~g}$ to $0.2447 \mathrm{~g}$ (Fig. 4). This result is determined by the value of the spectral response. This process is seen in the matching results of the spectral response of the initial conditions to the target (Fig. 5).

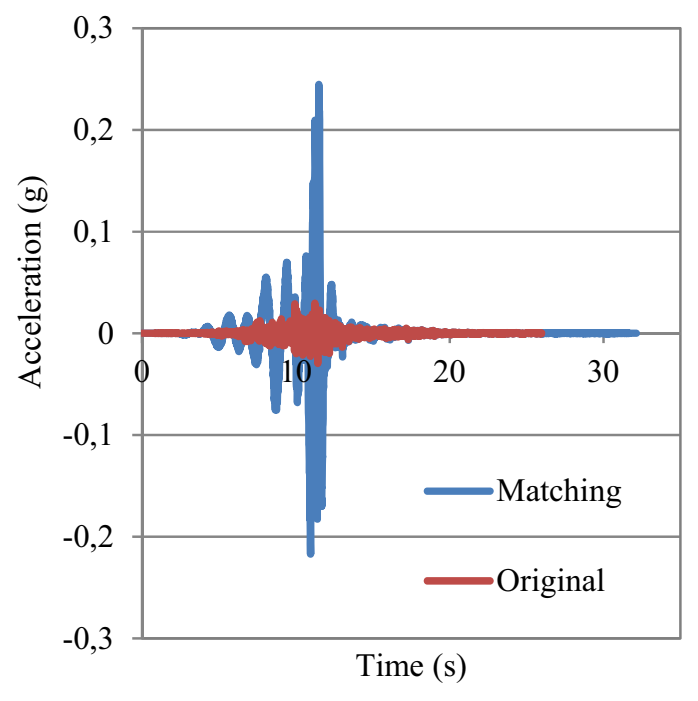

Fig. 4 Comparison of Time History

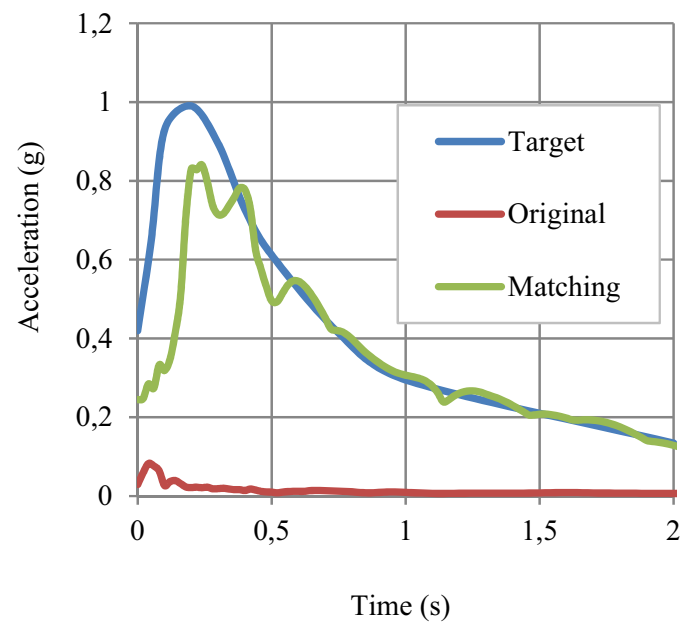

Fig. 5. Response Spectrum Acceleration

\subsubsection{Time History on Surface}

The earthquake wave propagation from the bedrock to the surface is done after the analysis process at the time history in bedrock. In this process, the dynamic ground parameter is inserted in each layer into NERA software. Dynamic soil parameters (Fig. 6) included are the maximum shear modulus value (Gmax) and shear wave velocity (Vs). The result of surface acceleration time after being moored from bedrock can be seen in Fig. 7 . 


\subsection{Structural performance evaluation}

Shear wave

velocity $(\mathrm{m} / \mathrm{s})$

$\operatorname{Gmax}(\mathrm{MPa})$
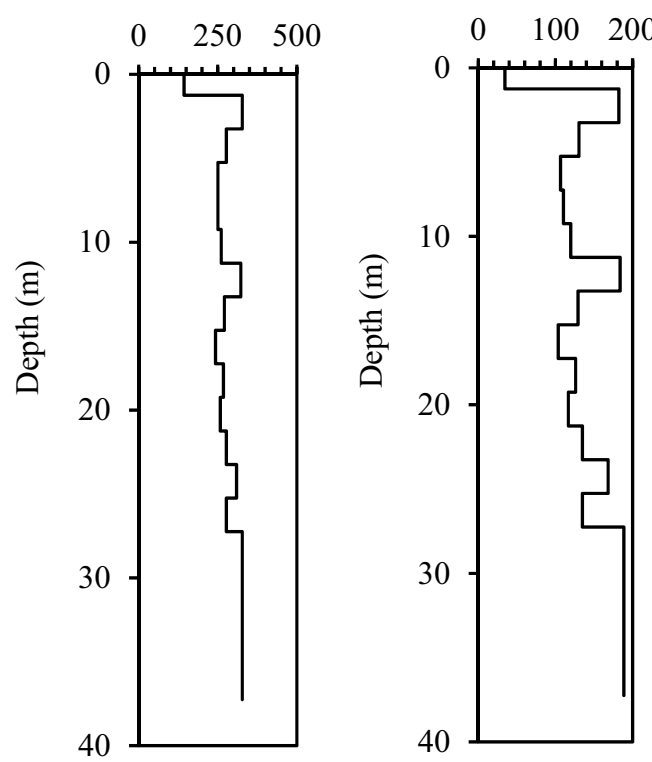

Fig. $6 G_{\max }$ and $V_{\text {s. }}$ to the depth at the research location

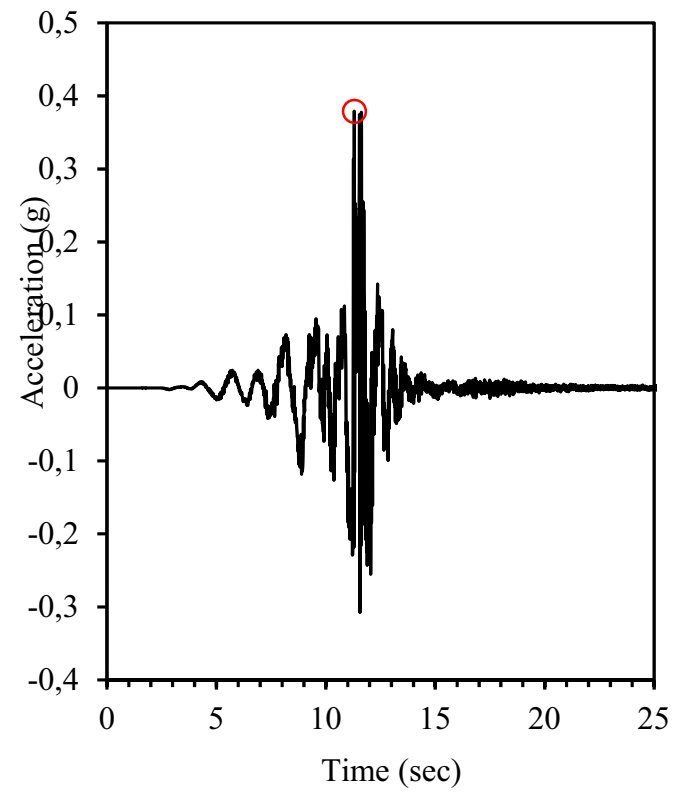

Fig. 7. Time History Acceleration in Surface

Based on the wave propagation results, the peak acceleration value increases on the surface after being propagated from the bedrock. The acceleration of the peak time acceleration time on the bedrock of $0.2447 \mathrm{~g}$ while the peak acceleration at acceleration time on the surface increased to $0.379 \mathrm{~g}$. From the result of surface positioning, has an effect of the amplification factor in the research area is 1.55 .

\subsubsection{Service performance limits}

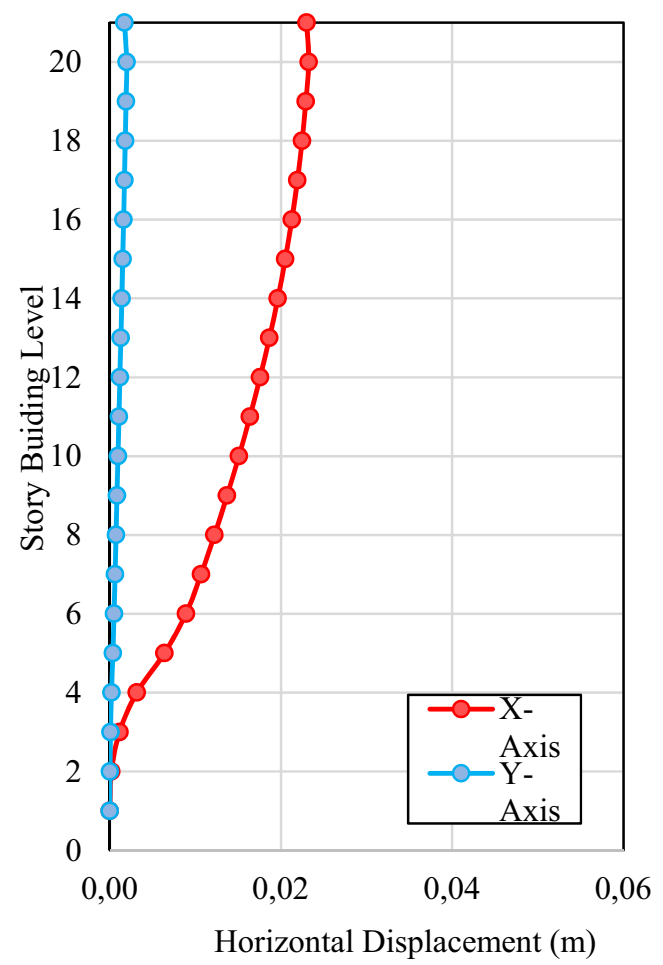

Fig. 8 Horizontal Displacement Pattern of Time History on Bedrock

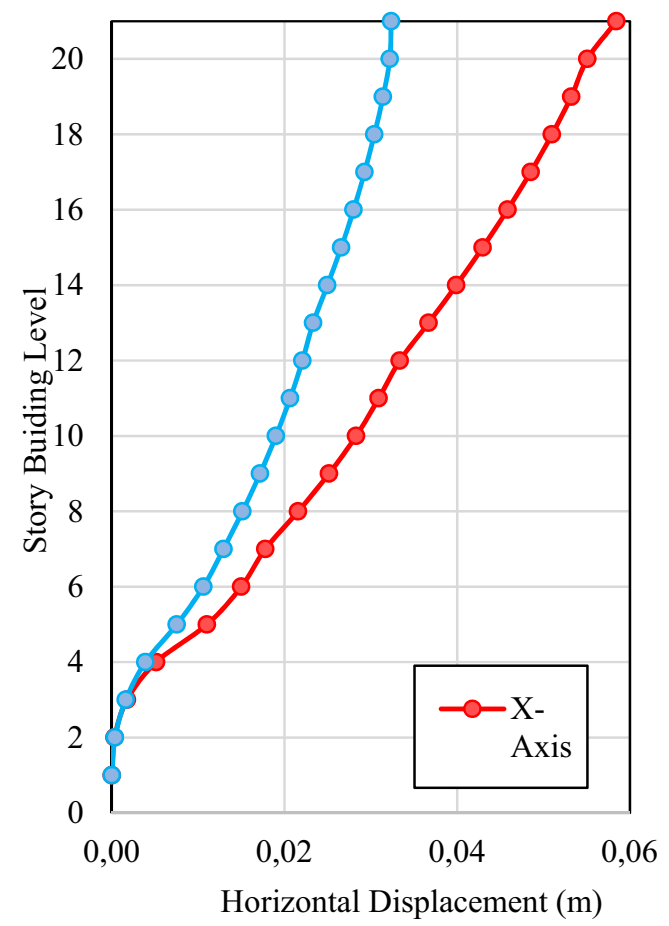

Fig. 9 Horizontal Displacement Pattern of Time History on Surface 


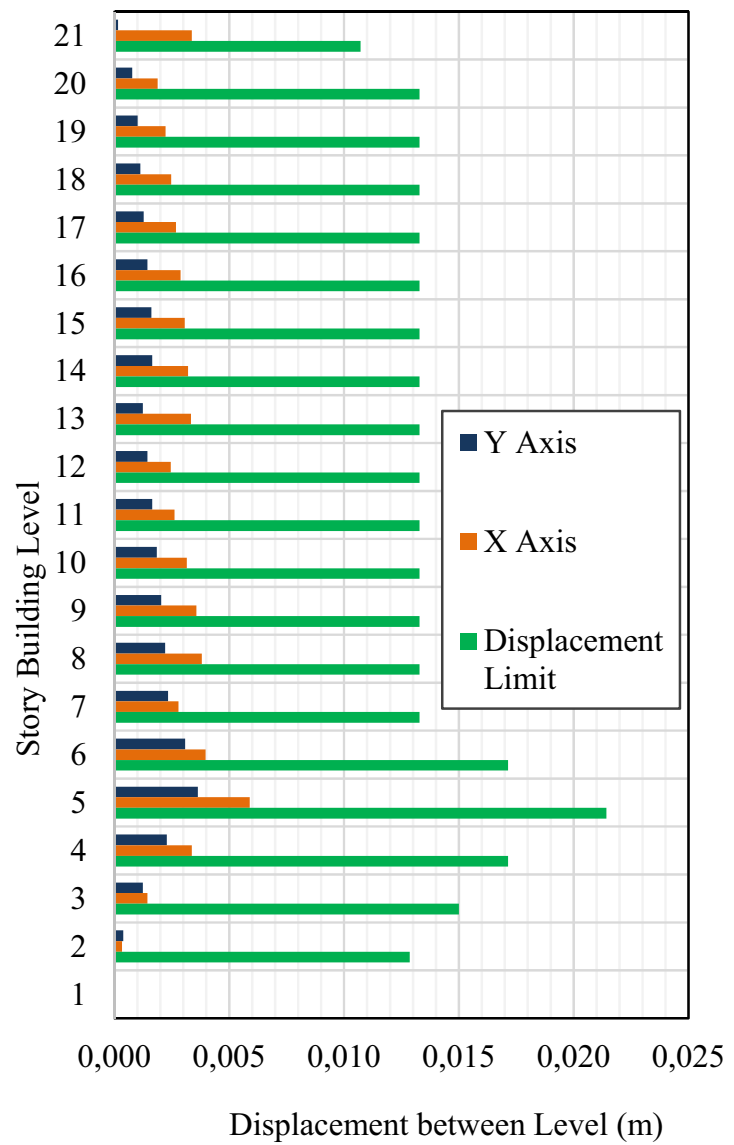

Fig. 10 Service performance limits

One parameter to determine the performance of a building structure is the value of service performance. This value can be calculated from the horizontal deviation between levels in the building structure. In Figs. 8-9, it can be seen that the horizontal displacement on the $\mathrm{X}$ axis has a higher value than the $\mathrm{Y}$ axis. The difference in the displacement value is due to the irregularity of the vertical configuration on the $\mathrm{X}$ axis, whereas, on the $\mathrm{Y}$ axis, it has a regular vertical configuration. The difference in the peak acceleration value in time history causes the horizontal displacement value in the time history on the bedrock to be smaller than the time history on the surface. Based on the analysis of service performance control in the $\mathrm{X}$ and $\mathrm{Y}$ axis, it can be concluded that the Alana Hotel is safe against the earthquake load. This conclusion is drawn from the displacement value between floors is still within the permitted limits. Graphical control of service performance limits due to earthquake time history load is shown in Fig. 10.

\subsubsection{Ultimate limit performance}

The ultimate limit performance in this study was calculated based on SNI 03-1726-2012. The parameter used to get the ultimate limit performance value is the displacement result from the SAP2000 output. Based on the ultimate limit performance control calculation in the $\mathrm{X}$-Axis and Y-Axis, the deviation of the floor that occurs is still within the criteria permit limit on the ultimate limit performance. The control chart of ultimate limit performance due to the time history earthquake load is shown in Fig. 11.

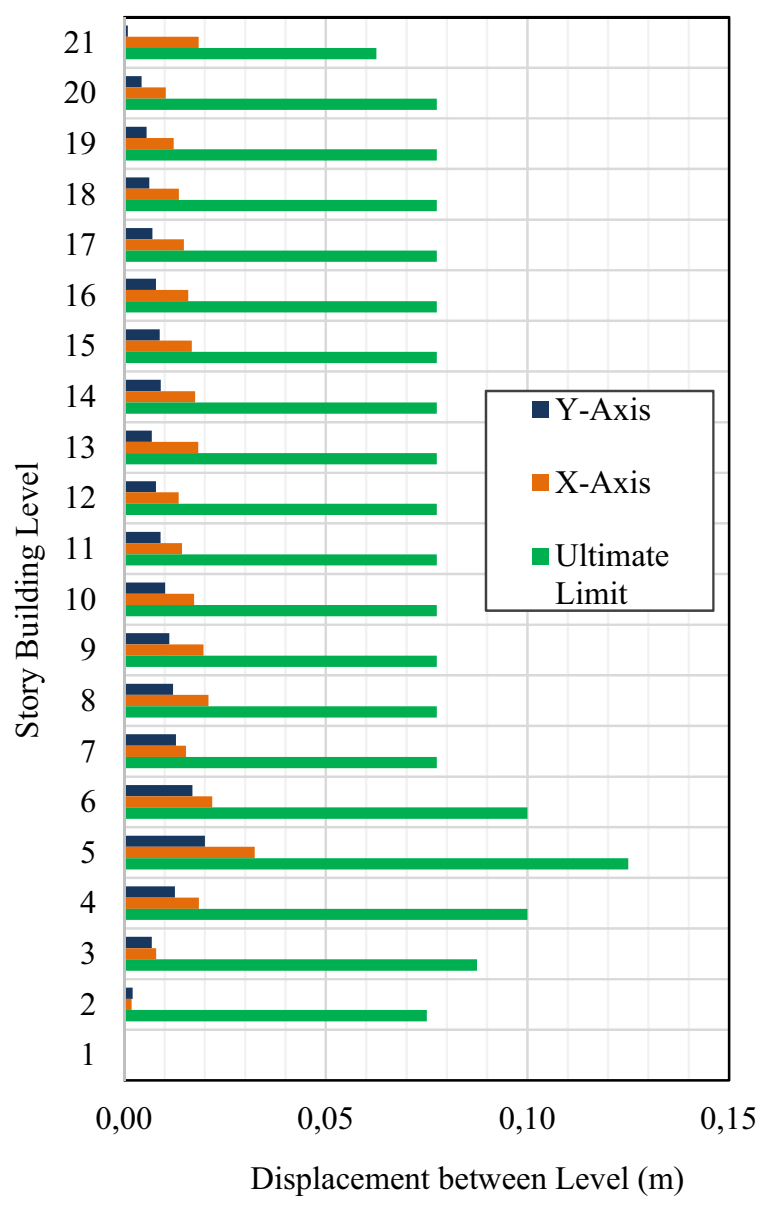

Fig. 11 Ultimate limit performance

\subsubsection{Drift ratio}

Evaluation results can be classified to determine the level of structural performance. One classification can be done by referring to the provisions of Applied Technology Council-40 (ATC-40). The classification carried out by the ATC-40 is to give the maximum drift ratio to the structure of the building. Drift ratio is defined as the ratio of deviation between levels to the displacement of the performance point against the height of the surface. The level of the performance level of a building, according to ATC-40, is measured based on the maximum drift of a building. The results of the analysis on the level of performance of the Alana Hotel structure by loading earthquake time history in the direction of $\mathrm{X}$ and $\mathrm{Y}$ results in a maximum drift value of less than $1 \%(0.01)$ and a Maximum inelastic drift value of less than $0.5 \%(0.005)$. Based on the analysis, it can be concluded that the performance level of the Alana Hotel following Table 3 is Immediate Occupancy (IO). The drift ratio on each floor as a whole can be seen in Figs. 11-12. 


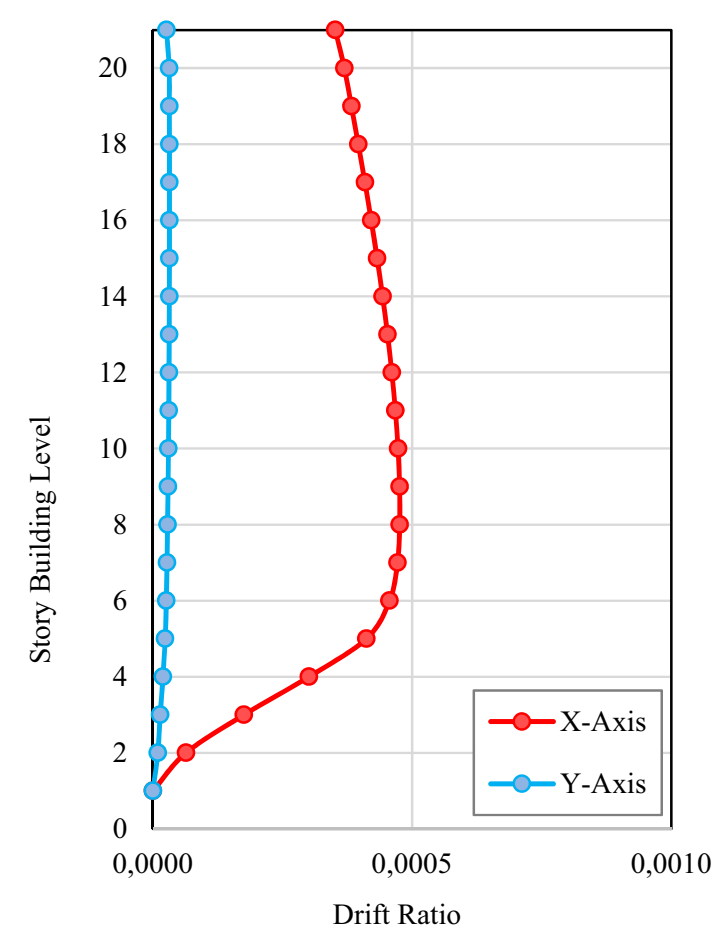

Fig. 11 Drift ratio on each floor of time history on bedrock

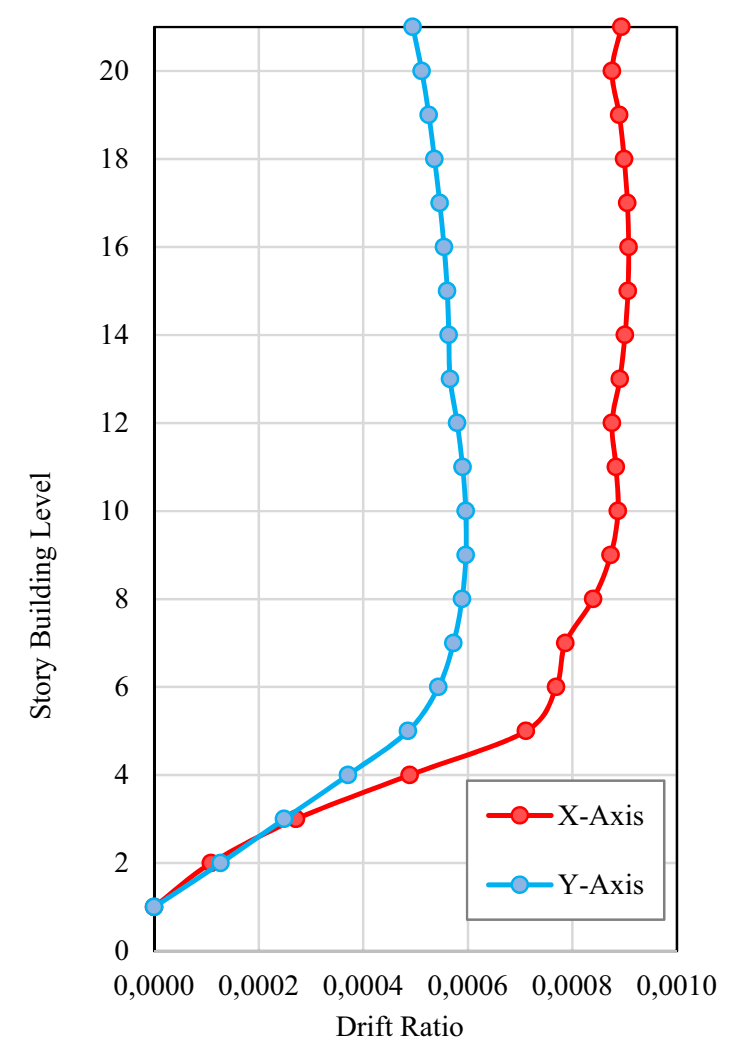

Fig. 12 Drift ratio on each floor of time history on the surface

Based on the shape of the building model, the $\mathrm{x}$-axis direction has a stiffness level that is weaker than the yaxis direction. The level of stiffness also affects the value of the drift ratio on the $\mathrm{x}$-axis and $\mathrm{y}$-axis. Besides that, one of the factors that influence the value of the drift ratio is the amount of peak acceleration in time history.

\section{Conclusion}

The results of the building analysis using a time history of the subduction earthquake source, based on the regulation of SNI 03-1726-2012, FEMA 356, and ATC-40, it was concluded that the performance level of the Alana Hotel is Immediate Occupancy (IO). The results of the analysis can be described in several important points.

a. The results of performance control of service limits at the Alana Hotel using earthquake loading in the form of time history derived from earthquake hazard analysis of subduction earthquake sources have fulfilled service performance requirements. Displacement values that occur on each floor do not exceed the maximum limit so that this building has fulfilled the requirements.

b. The ultimate limit performance results in the Alana Hotel using time history from subduction earthquake sources have met the ultimate limit performance requirements. Limitation of the permit for inter-level displacement due to earthquake loading does not exceed the permitted limit so that this building is feasible for use.

c. The results of the evaluation of the structural performance level, referring to the provisions of the Applied Technology Council-40 (ATC-40), produce a maximum drift value of less than $1 \%(0.01)$. Based on the ATC-40 classification, the performance level of the Alana Hotel is Immediate Occupancy (IO).

\section{References}

1. Widodo, Technical Seismology \& Seismic Engineering, Pustaka Pelajar, Yogyakarta (2012)

2. USGS. USGS Earthquake Preliminary Report (2006)

3. Mahesworo, R. P. Proposed Ground Motion for Four Big Cities in Sumatra Region Based on the Results of Seismic Hazard Analysis Using a 3Dimensional Earthquake Source Model, thesis, ITB (2008)

4. Irsyam, et al. Summary of Results of the Indonesia Earthquake Map Revision Team Study, Bandung (2010)

5. M. Teguh, and W. Erlangga, J of GEOMATE, 17, (63) 77 -86 (2019)

6. Kertapati, E.K, Earthquake Activities in Indonesia, Geological Survey Center, Bandung (2006)

7. Crouse. C.B. Ph.D., P.E. Associate, Seismic Hazard Evaluation Offshore Northwest Java, Indonesia, Report Maxus/ARII Offshore Indonesia Area (1992)

8. FEMA 356, Prestandard and Commentary for the Seismic Rehabilitation of Buildings, Federal Emergency Management Agency, Washington D.C (2000) 
9. ATC-40. Seismic Evaluation and Retrofit of Concrete Buildings, Vol 1, Aplied Technology Council, Redwood City, California, USA (1996)
10. SNI 1726-2012. Planning Procedures for Earthquake Resilience for Buildings and NonBuilding Buildings, National Standardization Agency (BSN), Jakarta (2012) 